\title{
Erratum to: Body Dissatisfaction and the Relevance of Religiosity: A Focus on Ultra-Orthodox Jews in a Community Study of Adult Women
}

\author{
Marjorie C. Feinson ${ }^{1}$ - Tzipi Hornik-Lurie ${ }^{2}$
}

Published online: 11 February 2016

(C) Springer Science+Business Media New York 2016

\section{Erratum to: Clin Soc Work J DOI 10.1007/s10615-016-0574-5}

During the production process, footnote indicators " $\mathrm{a}$ " and "b" on the section headings in Table 2 (a. Modern Orthodox and Ultra-Orthodox ${ }^{\mathrm{a}}$ and b. Secular and
Traditional $^{\mathrm{b}}$ ) corresponding to the footnotes ${ }^{\mathrm{a}}$ Above the diagonal: Modern Orthodox $(\mathrm{n}=181)$. Below the diagonal: Ultra-Orthodox $(\mathrm{n}=259)$ and ${ }^{\mathrm{b}}$ Above the diagonal: Secular $(\mathrm{n}=179)$. Below the diagonal: Traditional $(n=166)$ were removed inadvertently. This has been corrected in the published version.

The online version of the original article can be found under doi:10.1007/s10615-016-0574-5.

Marjorie C. Feinson

mcfnew@gmail.com; falk1@012.net.il

1 Falk Institute for Behavioral Health Studies, Kfar Shaul, Givat Shaul, 9382408 Jerusalem, Israel

2 Faculty of Health Sciences, Ben-Gurion University of the Negev, Beersheba, Israel 